Buca Eğitim Fakültesi Dergisi, 2021, say1 52, s. 77-96

Araştırma Makalesi
The Journal of Buca Faculty of

Education, 2021, issue 52, p. 77-96

Research Article

\title{
Nanoteknoloji Öğretimi Üzerine Yapılan Çalış̧maların Uluslararası Literatür Kapsamında Tematik İncelenmesi
}

\section{A Thematic Investigation of Studies on Teaching Nanotechnology in the Scope of International Literature}

Tamer YILDIRIM ${ }^{1}$

\author{
${ }^{1}$ Sorumlu Yazar, Dr. Öğretim Üyesi, Kimya Ĕgtimi Anabilim Dalı, Ĕgitim Fakültesi, Çanakkale \\ Onsekiz Mart Üniversitesi, Türkiye, kimyaci08@hotmail.com, (https://orcid.org/0000-0001- \\ 8605-5384)
}

Geliş Tarihi: 09.12.2020

Kabul Tarihi: 28.10.2021

Öz

Maddenin nanometre seviyesinde incelenmesi ve işlenmesi ile ilgilenen nanoteknoloji, popüler bir alan olması ve disiplinler arası doğası gereği eğitim çalışmalarının öncelik vermesi gereken bir alandır. Eğitimcilere yol gösterici olması amacıyla bu çalışmada; uluslararası literatür incelenerek nanoteknoloji öğretim çalışmalarında kullanılan kavramlar/konular tematik olarak analiz edilmiş ve yapılan etkinlikler derlenerek sentezlenmeye çalışılmıştır. İnceleme sonucunda nanoteknoloji öğretim çalışmalarında en çok kullanılan kavramlar; boyut/ölçek, boyuta bağlı özellikler, nano duyalı aletlerin yapısı, nanoteknoloji uygulamaları, nano malzemeler ve nano teknolojinin etik unsurları olmuştur. Bu kavramların öğrenilmesine yönelik olarak farklı deneysel etkinlikler, modelleme çalışmaları, video ve görsel araçlar, bilim merkezi gezisi ve tartışma etkinlikleri yapıldığı görülmüştür. Yapılan çalışmanın öğretmenlere, araştırmacılara, öğrencilere ve nano eğitim etkinliklerine katkı sunacağı düşünülmektedir.

Anahtar Kelimeler: Nanobilim, nanoteknoloji, nano etkinlik, nano öğretim, okullarda nano.

\begin{abstract}
Nanotechnology, which deals with the examination and processing of matter at the nanometer level, is a field that should be prioritized by educational studies due to its popular and interdisciplinary nature. In this study, the researches carried out on nanotechnology education in the journals reviewed within the international index are examined, while also carrying out a thematic analysis on the activities implemented within the content of nanotechnology education. It can be seen that there are six themes standing out within the examined studies, which are size/scale, size dependent properties, instrumentation used in nanotechnology, applications in nanotechnology, nano-materials, benefits and risks of nanotechnology. It was seen that different experimental activities, modeling studies, video and visual tools, science center visit and discussion activities were done to learn these concepts. It is considered that the study will contribute to teachers, researchers, students and nano education activities.
\end{abstract}

Keywords: Nanoscience, nanotechnology, nano activity, nano education, nano in schools.

\section{GíRiş}

Nanoteknoloji, 1şık mikroskoplarıyla dahi görülemeyen ultra küçük parçacıklarla ilgilenen disiplinler arası bir bilim dalıdır. Cüce anlamına gelen nano sözcüğüne ithafen 
nanobilim ve nanoteknoloji ismi kullanılmaktadır. 21. yüzyılın yeni sanayi devrimi olarak görülen nanoteknoloji, milimetrenin milyonda birine eşit olan nanometre boyutunda ( $1 \mathrm{~nm}-100$ $\mathrm{nm})$ maddelerin incelenmesi ve manipüle edilmesi işidir. Maddelerin atom ve molekül düzeyinde incelenip işlenmesini içeren fizik, kimya, biyoloji, mühendislik ve malzeme bilimlerinin disiplinler arası çalışmasıdır (Gardner, Jones ve Falvo, 2009; Hingant ve Albe, 2010; Jones ve diğerleri, 2013). 1980’li yıllarda önce Taramalı Tünelleme Mikroskobunun (STM) ardından da Atomik Kuvvet Mikroskobunun (AFM) geliştirilmesi ile nanoteknoloji devriminin başladığını söylenebilir. STM'nin 1981 yılında icadı ile bilim insanları maddeleri artık mikrometreden daha küçük ölçü birimi olan nanometre seviyesinde görüntülemeyi başardı. 1986 yılında AFM'nin icadıyla da maddeleri atom ve molekül düzeyinde resmetme ve taneciklerin yerlerini değiştirip kontrol edebilme başarılmış olundu (Erkoç, 2007; Planinšič ve Kovač, 2008). Böylece makro düzeyden çok farklı davranış sergileyebilen elektronikten, tıbba, gıdadan tekstile farklı alanlarda malzemeler geliştirilmeye başlanmış ve hızla büyüyen nanobilim alanı ortaya çıkmış oldu. Günümüzde hayatımıza giren nanoteknolojik ürünlere; elektronikte akıllı telefonlar ve nano bilgisayar çipleri, sağlıkta nano aygitlar ve akıllı ilaçlar, savunma sanayinde hafif silahlar, tekstilde 1slanmayan ve kendi kendini temizleyebilen giysileri sayılabilir (Erkoç, 2007). Hayat kalitesini arttıracak sağlam ve dayanaklı ürünlerin yapılmasına yol açan bu teknolojinin gerekliliği de ortadadır. Nanoteknolojinin dünya ekonomisinde önemli bir yer tutacağına dair büyük bir kabul vardır (Jackman ve diğerleri, 2016). Hızla büyüyen nanoteknoloji alanı kamu ve özel sektörden önemli yatırımlara yol açmıştır. Bilim insanları 2020 yılına kadar dünya çapında 6 milyon kalifiye işçiye ihtiyaç duyulacağını öne sürdüler. Bu daha önce yapılan 2015 tahmini iş gücünün üç katıydı (Roco, Mirkin ve Hersam, 2011). 2020 yılı hedefine ulaşıldığını doğrulayan bir çalışmaya henüz rastlanmasa da 2015 yılı tahmininin aşıldı̆̆ı rapor edilmiştir. Nanateknoloji iş gücü ve piyasası her üç yılda bir, ikiye katlanarak büyümektedir. 2030 yılına kadar gelişmiş ekonomilerin gayrisafi yurtiçi hasılanın (GSYİH) yaklaşık \%10'undan fazlası nanoteknoloji gelirlerine ait olacağı tahmin edilmektedir (Roco, 2018).

Hızla artan nitelikli iş gücü ihtiyacını karşılamada en önemli sorununun nanoteknoloji eğitimi olacağı vurgulanmıştır (Roca, 2003). Disiplinler arası bir alan olmasından dolayı nanoeğitimin hangi bilim dalı tarafindan yapılacağı ve hangi seviyelerde müfredata girmesi gerektiği tartışılmıştır (Stevens, Sutherland, Schank ve Krajcik, 2009). Bu konuda öncülügü ABD çekmiş ve Ulusal Bilim Vakfı (NSF) destekleri ile çeşitli atölye çalışmaları, bilim kampları ve bilim sergileri ile katılımcıların nanobilim anlayışlarını artırıcı etkinlikler düzenlenmiştir. "Nanosense", "nanodays", "NanoLeap", "nisenet" bu projelerden bazılarıdır. Avrupa Birliği de bilim atölyeleri şeklinde okullarda ve üniversitelerde nanoeğitimin yapılmasını sağlayan projeleri desteklemiştir (Mallman, 2008). NTSE (Nano Technology Science Education), "Nonoyou", "irresistible", "NanoTouch" projeleri örnek verilebilir. ABD Ulusal Bilim Vakfi ve Nano Ölçekli Bilim ve Mühendislikte Ulusal Öğrenme ve Öğretme Merkezi tarafından finanse edilen "The Big Ideas of Nanoscience" projesi bunların en geniş kapsamlı ve sistematik olanıdır. $\mathrm{Bu}$ proje, okul müfredatına dâhil edilmesi gereken kavramları ve NST'nin (Nano Science Technology) ana unsurlarını belirlemeyi amaçlayan atölye çalışmalarını içerir (Stevens ve diğerleri, 2009). Benzer şekilde ortak akıl oluşturmak amacıyla delphi çalışmalarıda yine NSF tarafindan organize edilmiştir (Wansom ve diğerleri, 2009). Literatürde nanoeğitimin hangi düzeyde yapılmasına ilişkin iki ana görüş vardır. Birincisi nano ile ilgili konuların anlaşılmasının zorluğu ve bilimsel birikim gerekliliğine dayanarak nanobilim ve nanoteknoloji kavramlarının yükseköğretimde öğretilmesidir (Kulik ve Fidelus, 2007). İkinci görüşe göre ise bilim okuryazarı nesiller yetiştirmek ve onları geleceğe en iyi şekilde hazırlamak için ortaokul ve liselerde nanobilim ve nanoteknoloji eğitimine başlanması gerektiğidir (Schank, Krajcik ve Yunker, 2007).

ABD'de nanobilim alanında müfredat ve eğitim modüllerinin geliştirilmesine yönelik acil eylem çağrıları yapılmıştır (Murday, 2009). Nanobilim ve nanoteknolojinin (NBT) okul müfredatına dâhil edilmesi için NSF, bir dizi atölye çalışmasını desteklemiştir. Kapsamlı 
çalışmaların sonucunda okullarda NBT hakkında öğretilmesi gerektiği düşünülen konular "Dokuz Büyük Fikirler "adıyla ortaya çıkarılmıştır (Stevens ve diğerleri, 2009). Bu başlıktaki "büyük fikirler" ifadesi, öğrencilerin nano fenomenleri anlamalarını sağlayacak temel kavramları belirtir (Hingant ve Albe, 2010). Bundan sonraki çoğu nanoeğitim çalışmalarına kaynaklık edecek olan bir "fikir birliği belgesi" bu şekilde oluşturulmuştur. Orta dereceli okullar (7-12. sınıf) için önerilen bu dokuz maddelik "büyük fikirler" şunlardır:

1. Boyut ve Ölçek

2. Maddenin Yapis1

3. Kuvvetler ve Etkileşimler

4. Kuantum Etkileri

5. Boyuta Bağlı Özellikler

6. Kendi Kendine Montaj

7. Araçlar ve Enstrümanlar

8. Modeller ve Simülasyonlar

9. Bilim, Teknoloji ve Toplum.

İlk dört fikir, nanobilimin anlaşılmasını sağlayan temel kavramları, sonraki ikisi (5 ve 6), nano fenomeni açıklamak için ilk dört kavramın kullanılmasını sağlayan etkinlikleri, 7 ve 8 ise nano ölçekli fenomenleri ölçerek, incelemesini ve geliştirmesini sağlayan nano duyarlı aletler ile ilgilidir. 9. fikir, NBT uygulamaları, bunun toplumdaki sonuçları ve etik yansımaları ile ilgilenir (Gilbert ve Lin, 2013).

Nanoeğitim için ortaya konulan bu "büyük fikirler"den sonra son 10 y1lda uluslararası alanda birçok çalışma yapılmıştır. Bunlardan önemli bir kısmı okul dışı bilimsel kamplarda lise öğrencilerine çeşitli etkinliklerle nanobilim ve nano teknoloji alanında eğitim verme üzerine gerçekleşmiştir (Adadan, Akaygun ve Sanyal, 2017; Blonder ve Dinur, 2011; Blonder ve Sakhnini, 2012; Lati, Triampo ve Yodyingyong, 2019; Schwarzer ve diğerleri, 2015). Yine önemli bir miktarda çalışma sınıflarında nanoeğitim yapması beklenen fizik, kimya, biyoloji ve fen öğretmenlerine yönelik yapılan çalışmalardır (Blonder, 2010; Blonder, 2011; Blonder ve Mamlok Naaman, 2016; Blonder ve Sakhnini, 2012; Sakhnini ve Blonder, 2016; Sakhnini, ve Blonder, 2018; Sgouros, ve Stavrou, 2019; Stavrou, Michailidi ve Sgouros, 2018). Bunların dışında ilköğretim ve yükseköğretim öğrencilerine yönelik araştırmalar da mevcuttur (Mandrikas, Michailidi ve Stavrou, 2020; Lin ve diğerleri, 2015; Zor ve Aslan, 2018). Ülkemizde ise nanoeğitime yönelik yapılan çalışmalar oldukça sınırlı sayıdadır (Alpat ve diğerleri, 2017; Demircioğlu ve Özdemir, 2019; Sagun Gököz ve Akaygün, 2013). Türkiye'de nanoteknoloji stratejik teknoloji alanlarından biri olarak kabul edilmiş ve ilgili bilimsel kuruluş olan TÜBİTAK tarafindan öncelikle desteklenen alanlardan biridir (Denkbaş, 2015). Buna rağmen nanoeğitim alanında yeterli araştırmanın yapılmadığı görülmektedir. Boğaziçi üniversitesi öncülügünde birkaç AB projesi ("irresistible") ortaklığı ve TÜBİTAK 4005 projesi (nanoteknoloji kulüpleri) ve bireysel tez çalışmaları (Şenel Zor, 2017; Sagun Gökoz, 2012) haricinde nanoeğitime yönelik kapsamlı çalışma bulunmamaktadır. Bunun nedenlerinden biri nanoteknolojinin disiplinler arası olması nedeni ile eğitim bilimcilerin yeterli bilgi birikime sahip olmamaları olabilir. Diğer bir neden ise bu yeni alanı, birçok eğitimci hangi kavramlarla ve nasıl öğretileceğini bilmiyor olmasıdır (Healy 2009; Jones ve diğerleri, 2013).

Ülkemizdeki nanoeğitim çalışmalarının yetersizliği ve eğitimcilerin aşina olmadıkları bu konuda kendilerini eksik hissetmeleri çalışmamızın ana gerekçeleri olmuştur. Bu gerekçelerle araştırmanın amacı, eğitim ortamlarında NBT öğretiminin hangi kavramlarla ve ne şekilde yapılacağına yönelik uluslararası literatür 1şı̆̆ında derleme yapmaktır. Uluslararası literatür incelenerek nano eğitimcilere yol gösterecek kavramsal içerikler sentezlenmeye çalışılmıştır. Nanoteknoloji alanının popülerliği ve disiplinler arası doğası yani Fen, Teknoloji, Mühendislik ve Matematik Eğitimi (STEM) alanı olması çalışmayı önemli kılmaktadır. Çalışmamızın ana problemi eğitimciler NBT öğretimini hangi konu/kavramlarla ve ne şekilde yapabilir? Alt sorular ise şunlardır: 
- Uluslararası literatürde NBT öğretimi en çok hangi konular/kavramlarla işlenmişsir?

- Uluslararası literatürde NBT öğretimi nasıl yapılmaktadır?

\section{YÖNTEM}

$\mathrm{Bu}$ çalışma nitel araştırma desenlerinden içerik analizi yöntemi ile yürütülmüştür. Uluslararası indekste taranan dergilerdeki NBT öğretimi üzerine yapılmış araştırmalar gözden geçirilmiş ve öğretiminde kullanılan etkinliklerin tematik içerik analizi yapılmıştır. Araştırmalarda işlenen NBT öğretim kavramlarının sentezlenmesine çalışılmıştır. Tematik içerik analizi, belli bir konu üzerinde yapılmış olan çalışmaların temalar ya da belli şablonlar altında incelenip eleştirel yaklaşımla yorumlama işidir. Konu bütüncül bir yaklaşımla ve derinlemesine incelenir. Tematik içerik analizinin bir faydası da belli bir konunun literatürdeki ortak ve benzer yönlerinin nitel olarak sentezlenmesini ve örneklendirilmesini sağlamasıdır (Çalık ve Sözbilir, 2014).

Nanobilim ve nanoteknoloji literatürünü kullanarak gelecekteki araştırmalar ve okul/fakülte/atölye çalışmaları için bazı öneriler sağlamak üzere bu araştırma tasarlanmıştır. İnceleme için Web of Science, EBSCOhost, ERIC, Education Full Text indekslerinde nanoteknoloji, okullarda nanoteknoloji, nanoteknoloji etkinlikleri, nanoteknoloji eğitimi ve nanoöğretim anahtar terimleri kullanılarak arama yapılmıştır. Uluslararası alanda kabul gören alan indekslerde yayımlanan makalelerin seçilmesinin sebebi bu veri tabanlarında makaleler uluslararası standartlara uygun ölçütlerle değerlendirme sürecinden geçtiği ve adı geçen indekslerdeki yayınların daha güvenilir sonuçlar sağlayacağı düşünülmüştür (Gül ve Sözbilir, 2015). 2010 yılından sonra yayımlanan makeleler araştırma kapsamına alınmıştır. Nanoteknolojinin yeni bir alan olması ve eğitim çalışmalarındaki güncel durumu tespit etmek için bu zaman aralığı tercih edilmiştir. Arama sonucunda 43 makaleye ulaşılmış. Bunlar içinde nanoteknolojiye yönelik belli konu ve kavramları öğretmeyi amaçlamış ve deneysel uygulama ile etkinlik temelli çalışmalar bu araştırmaya dahil edilmiştir. Diğer çalışmalar elenerek 19 makale (Ek-1) tematik içeriğe göre kategorize edilmiş ve sonuçlar sentezlenerek yorumlanmıştır. İncelenen makalelerin nicel yönleri hariç tutularak, çalışmalarda işlenen NBT'ye yönelik kavram ve etkinlikler nitel olarak karşılaştırılıp sentezlenmeye çalışılmıştır. $\mathrm{Bu}$ açıdan çalışma bir anlamda meta sentez çalışmasıdır.

Öncelikle çalışmaya dâhil edilen her bir makalenin öğretim çalışması (instruction) yani uygulama bölümü dikkatli bir biçimde okunmuş ve elde edilen veriler makale üzerinde not edilmiştir. Daha sonra veriler tekrar kontrol edilerek farklı çalışmalardaki benzer veriler bir araya getirilmeye çalışılmıştır. Makalelelerin ne amaçla yapıldığı, hangi öğretim yöntemi ile yürütüldügü, çalışma grupları, yapılan etkinlikler ve etkinliklerde seçilen kavramlar kodlanarak bilgisayar ortamına kaydedilmiştir. Makaleler, araştırmada kullanılan uygulama etkinliklere göre tekrar tekrar incelenmiş, temalar ve bunlara yönelik kodlar oluşturulmuştur. Kodlama yapılırken NBT öğretim etkinliklerinin hangi konu/kavram üzerine yapıldığına, ne tür öğrenme yaklaşımı kullanıldığına ve hangi etkinlikler ile derslerin yürütüldüğüne dikkat edilmiştir. Örneğin incelenen bir çalışmada; nano ölçeğin ne kadar küçük olduğunu öğrencilere göstermek için yapılan kağıt kesme etkinliği kodlanırken konu/kavram olarak "büyük fikirler" deki boyut/ölçek kavramı, etkinlik olarak ise kağıt parçasını nano boyutta kesmeye çalışma kodları tercih edilmiştir. Yapılan etkinliğin deney, oyun, modelleme vb şekilde yürütülme durumları ayrı olarak kodlanmıştır. Bu şekilde oluşturulan kodlar birleştirilerek kategorize edilmiş ve tablolar halinde sunulmuştur. Aynı çalışmada birden fazla konu ve etkinlik olduğundan etkinlik toplamı incelenen çalışma toplamından fazla olabilir. Daha sonra oluşturulan kategoriler nitel ve bütüncül bir yaklaşımla sentezlenmeye çalışılmıştır. Kodlamalar yazar tarafından güvenilirliğin sağlanması için bir ay arayla iki kez incelenip kodlanmıştır. Makaleler, tekrar incelenip yeniden kodlanarak hata payı düşürülmüştür. Ayrıca yazar yaptığı örnek bir kodlama sürecini alanında uzman bir akademisyene inceleterek geçerliliği sağlamaya çalışmıştır. 


\section{BULGULAR}

Tematik analizi yapılan makalelerde NBT konularının öğretiminde en sık karşılaşılan kavramlar/konulardan biri "Boyut/Ölçek" kavramı olmuştur. Tablo 1'de "Boyut/Ölçek" kavramı üzerine yapılan çalışmaların hangi düzeylerde ve hangi etkinlikler ile yürütüldüğü sunulmuştur.

Tablo 1. Boyut/Ölçek Konusu Üzerine Yapılan Etkinlikler

\begin{tabular}{llll}
\hline Etkinlik & Türü & Örneklem Düzeyi & Makale Kodlar1 \\
\hline $\begin{array}{l}\text { Kağıt parçasını nano ölçekte } \\
\text { kesmeye çalışma }\end{array}$ & $\begin{array}{l}\text { Düşündürücü } \\
\text { aktivite }\end{array}$ & $\begin{array}{l}\text { Ortaokul } \\
\text { Lise }\end{array}$ & M12, M18 \\
& & Öğretmen & M6, M15 \\
& & Ortaokul & M12, M18 \\
Farklı boyutlardaki cisimleri & \multirow{2}{*}{ Oyun } & Lise & M15 \\
sıralama etkinliği & & Üniversite & M19 \\
& & Öğretmen & M17 \\
& & İlkokul & M11 \\
Video izleme (medya görseli & Görsel tanitım & Ortaokul & M12, M17 \\
ile tanıtım) & & Lise & M6 \\
& & &
\end{tabular}

Tablo 1 incelendiğinde nano ölçekte boyut kavramının öğretiminde kağıt parçasını nano boyuta indirgeyecek kadar küçük parçalara kesmeye çalışma etkinliğinin, ortaokul, lise ve öğretmen gruplarında uygulandığı görülmektedir. İncelenen çalışmalarda nanometreden metreye kadar farklı büyüklükteki nesneleri nanoskalada sıralamaya çalışma oyun aktivitesi, tüm düzeylerde öğretim aktivitesi olarak uygulanmıştır. Bunlara ek olarak video, animasyon ve Şekil 1'dekine benzer nanoskala görsellerini kullanarak boyut ve ölçek kavramlarını öğretme çalışmaları da bulunmaktadır.

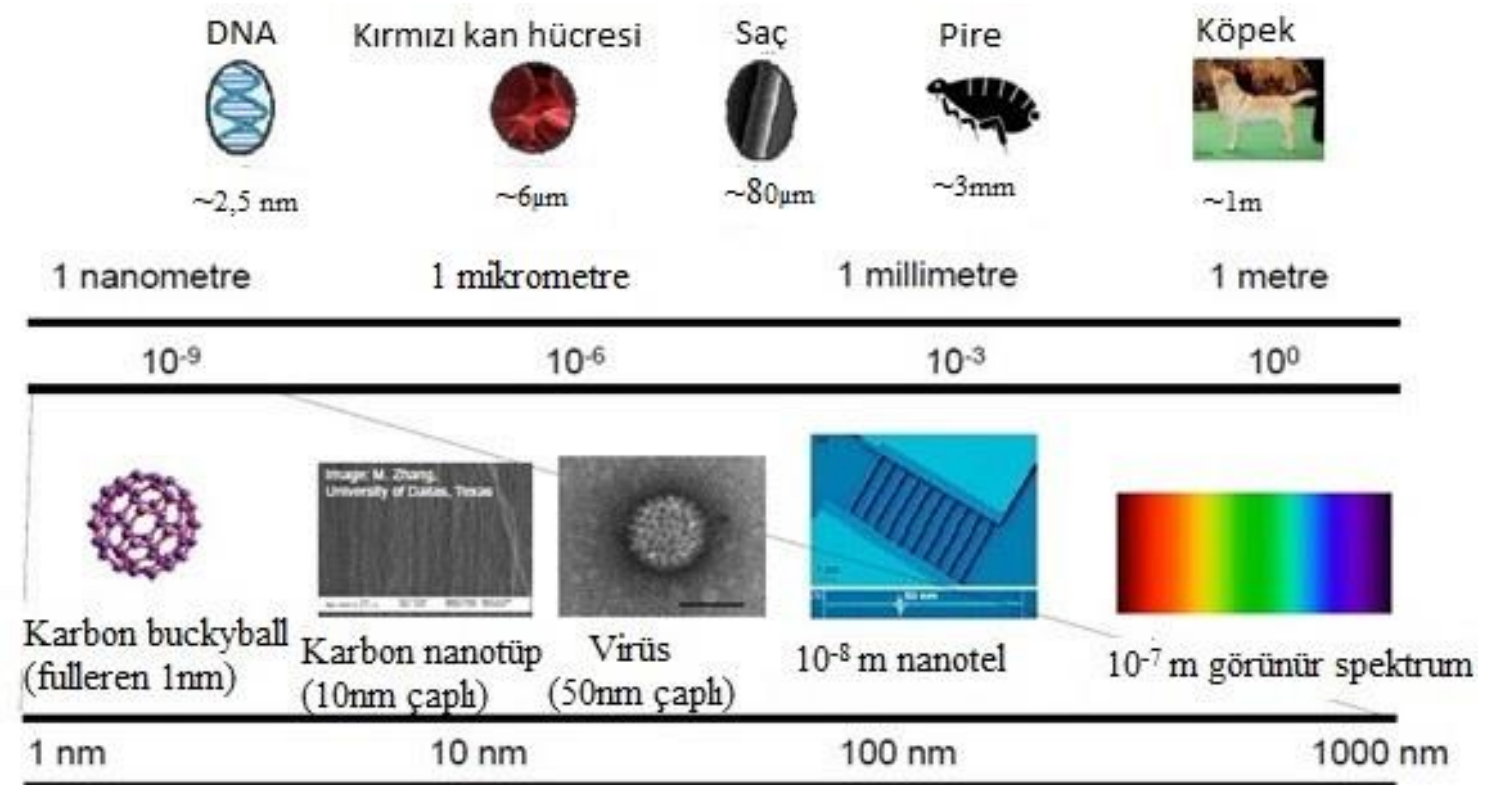

Şekil 1. Farklı Cisimlerin Nanoskalada Örnek Gösterimi (Nonoyou Project, 2016) 
İncelenen çalışmalarda sıklıkla işlenen bir başka konu ise "Boyuta Bağlı Özellikler (Yüzey/Hacim Oranı)“ olmuştur. Bu konunun işlendiği çalışmalarda yapılan etkinlikler ve özellikleri Tablo 2'de sunulmuştur.

Tablo 2. Boyuta Bağlı Özellikler Konusu Üzerine Yapılan Etkinlikler

\begin{tabular}{|c|c|c|c|}
\hline Etkinlik & Türü & Örneklem Düzeyi & Makale Kodları \\
\hline \multirow{3}{*}{$\begin{array}{l}\text { Küpleri farklı boyutlarda } \\
\text { küçülterek yüzey/ hacim } \\
\text { oranını hesaplama }\end{array}$} & \multirow{3}{*}{ Modelleme } & Ortaokul & M12 \\
\hline & & Lise & M6 \\
\hline & & Öğretmen & M5, M16, M17 \\
\hline \multirow{3}{*}{$\begin{array}{l}\text { Yüzey/Hacim oranı ile } \\
\text { reaksiyon hızını klyaslama } \\
\text { deneyi (efervesan tablet, agar } \\
\text { küpü, çelik tel vb.) }\end{array}$} & \multirow{3}{*}{ Deney } & Ortaokul & M18, M12 \\
\hline & & Lise & M1 \\
\hline & & Öğretmen & M16 \\
\hline Silika aerojel hazırlama & Deney & Lise & M10 \\
\hline
\end{tabular}

Tablo 2 incelendiğinde NBT öğretim çalışmalarında boyuta bağlı özellikler başlığı altında maddelerin boyutları küçüldükçe yüzey alanlarının hacimlerine oranının değiştiğini kavratmaya yönelik deneysel ve modelleme etkinliklerinin yapıldığı görülmektedir. Modelleme çalışmasında Şekil 2'de gibi cisimlerin küçük parçalara bölünmesi ve her bölünmüş parçanın yüzey alanının hacimine oranı hesaplanarak sonuçtaki değişimin fark edilmesi sağlanmaya çalışılmıştır. Deney etkinliği yapılan çalışmalarda ise "efervesan" tabletin suda çözünmesi, hidrojen peroksit ile patates parçalarının etkileşimi ve farklı kalınlıkta çelik tellerin yakılması gibi maddenin küçük parçalara ayrıldıkça reaksiyon hızındaki değişimin gösterilmesi amaçlanmıştır.

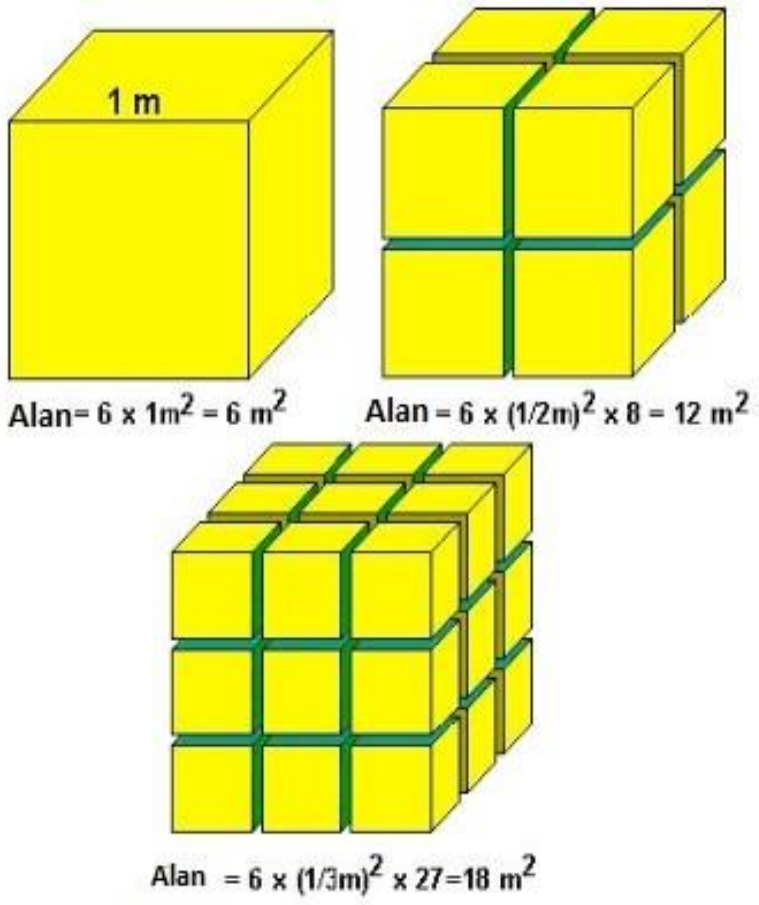

Şekil 2. Yüzey Alanı/Hacim Modeli (Nanosense Project, 2007)

İncelenen çalışmalarda öne çıkan bir başka konu ise nano boyutta görüntüleme ve müdahale etme araçlarının katılımcılara öğretilme etkinlikleri olmuştur. Yapılan etkinliklerin özellikleri Tablo 3'de sunulmuştur. 
Tablo 3. Nano Duyarlı Aletlerin Tanıtımı Üzerine Yapılan Etkinlikler

\begin{tabular}{|c|c|c|c|}
\hline Etkinlik & Türü & Örneklem Düzeyi & Makale Kodları \\
\hline \multirow{4}{*}{ AFM ve STM'i Tanıma } & \multirow{4}{*}{ Modelleme } & Ortaokul & M18 \\
\hline & & Lise & M15 \\
\hline & & Üniversite & M19 \\
\hline & & Öğretmen & M2; M5 M16 \\
\hline \multirow{3}{*}{$\begin{array}{l}\text { Nanateknoloji alanında } \\
\text { kullanılan araçları tanıma }\end{array}$} & \multirow{3}{*}{$\begin{array}{l}\text { Araştırma } \\
\text { merkezi } \\
\text { ziyareti }\end{array}$} & Ortaokul & M17, M12 \\
\hline & & Lise & M15 \\
\hline & & Öğretmen & M3, M5 \\
\hline \multirow{2}{*}{$\begin{array}{l}\text { Kara kutu (Kapalı kutu } \\
\text { içindeki nesneyi tanımlama) }\end{array}$} & \multirow{2}{*}{ Oyun } & Lise & M6, M15 \\
\hline & & Öğretmen & M16 \\
\hline \multirow{2}{*}{ 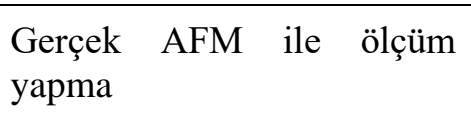 } & \multirow{2}{*}{ Deney } & Lise & M15 \\
\hline & & Öğretmen & M3 \\
\hline
\end{tabular}

Tablo 3 incelendiğinde farklı düzeydeki katılımcılara nanoteknolojide kullanılan görüntüleme ve karakterize etme araçlarının çalışma prensiplerini öğretmek için modelleme ile tanıtma ve kapalı kutu içindeki maddeyi tarif etme oyunu etkinliklerinin yapıldığı görülmektedir. Örnek bir AFM modeli Şekil 3'te görülmektedir. Şekil 3'te görüldüğ̈̈ gibi AFM, dirseğe bağlı bir ince uç ile bir yüzeyi tarayarak çalışır. Uç ile yüzey atomları arasındaki tanecikler arası etkileşimler sebebiyle uç yüzey tarafından itilip, çekildikçe dirsekten 1şın saptırılır. Sapma açısı bir lazer tarafindan belirlenerek cisim haritalandırılır (Blonder ve Sakhnini, 2012). Ayrıca nanoteknoloji araştırma merkezi ziyaret edilerek uzmanlarından nano duyarlı aletlerin tanıtımı ve AFM gibi cihazları ögrencilere kullandırmaya yönelik deneysel etkinlik yapıldığı anlaşılmaktadır.

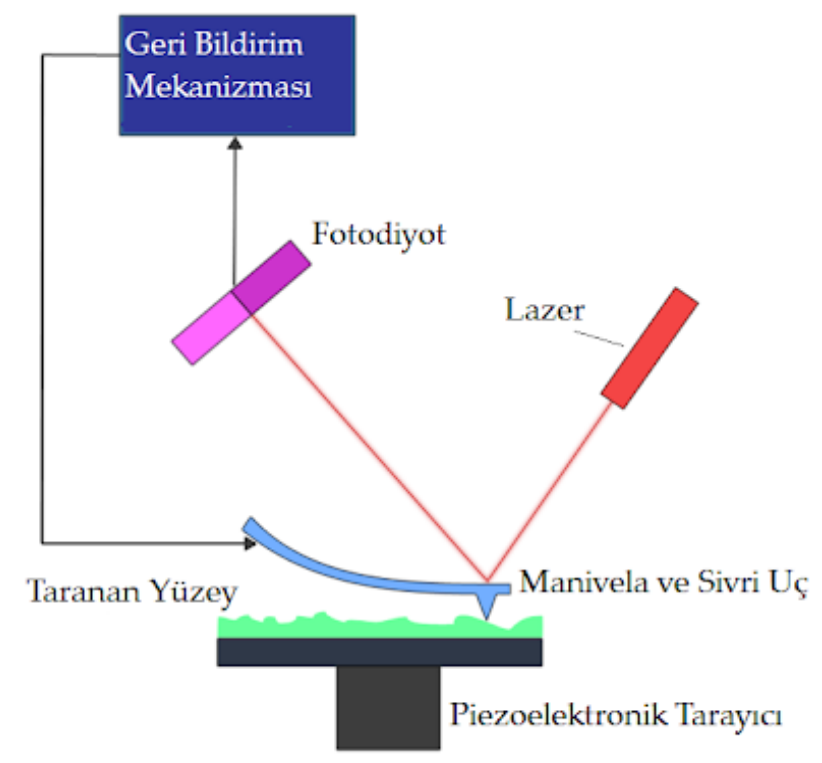

Şekil 3. AFM Diyagramı (The NISE Network, 2016)

Araştırma kapsamında incelenen NBT öğretimi çalışmalarında tercih edilen bir konuda "lotus etkisi" ve "kendi kendine nontaj" kavramlarının işlendiği doğadan yararlanılarak hayata 
geçirilen nanoteknoloji uygulamaları olmuştur. Bu konuda yapılan etkinliklerin özellikleri Tablo 4'de sunulmuştur.

Tablo 4. Nanoteknoloji Uygulamaları Üzerine Yapılan Etkinlikler

\begin{tabular}{|c|c|c|c|}
\hline Etkinlik & Türü & Örneklem Düzeyi & Makale Kodları \\
\hline \multirow{4}{*}{$\begin{array}{l}\text { Lotus etkisi (Yaprak ve farkl1 } \\
\text { yüzeylere su damlatma) }\end{array}$} & \multirow{4}{*}{ Deney } & İlkokul & M11 \\
\hline & & Ortaokul & M12, \\
\hline & & Üniversite & M19 \\
\hline & & Öğretmen & M16 \\
\hline \multirow{3}{*}{$\begin{array}{l}\mathrm{Su} \text { geçirmeyen ve kendini } \\
\text { temizleyen nano malzemeler }\end{array}$} & Deney & Ortaokul & M12 \\
\hline & $\begin{array}{l}\text { Araştırma } \\
\text { Merkezi } \\
\text { ziyaret }\end{array}$ & \multirow[t]{2}{*}{ Öğretmen } & M5 \\
\hline & $\begin{array}{l}\text { Sunum } \\
\text { Hazirlama }\end{array}$ & & M3 \\
\hline $\begin{array}{l}\text { Nanoteknoloji uygulamalarının } \\
\text { (nanotıp, nanoelektronik, } \\
\text { fotovoltaik hücreler, } \\
\text { nanobotlar ve kendi kendini } \\
\text { temizleme) öğretilmesi }\end{array}$ & $\begin{array}{l}\text { Delphi } \\
\text { yöntemi }\end{array}$ & Öğretmen & M13 \\
\hline $\begin{array}{l}\text { Silika aerojel ile montaj ve } \\
\text { temizlik }\end{array}$ & Deney & Lise & M10 \\
\hline
\end{tabular}

Tablo 4 incelendiğinde doğadaki maddelerin nano yüzeylerinden esinlenilerek geliştirilen nanoteknolojik malzemeleri tanıtma ve bunların altında yatan bilimsel sebepleri anlamaya yönelik öğretme çalışmaların olduğu görülmektedir. Şekil 4'te görülmekte olan lotus bitkisi gibi farklı yaprak yüzeylerine ve nano özellikte olan su geçirmez kumaş parçalarına su damlatarak hidrofob özelliğin anlaşılmasına yönelik farklı düzeylerde etkinliklerin yapıldığı tespit edilmiştir. Yine aynı konu ile ilgili kendi kendine montaj kavramının açıklamaya yönelik etkinlikler de görülmektedir. Ayrıca uzmanlar topluluğunun fikir birliği (delphi yöntemi) ile geliştirilen nanoteknolojinin 5 temel uygulamasını okullarda öğretmek için bağlam oluşturma çalışmasının yapıldığı anlaşılmaktadır.

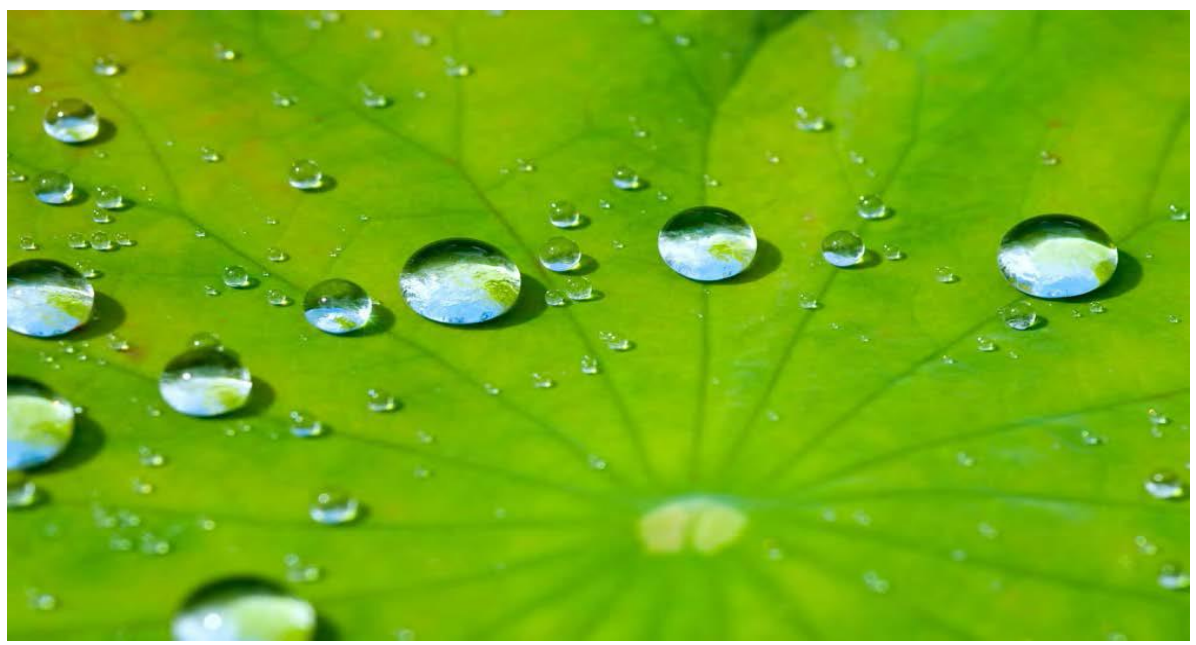

Şekil 4. Lotus Yaprağı (The NISE Network, 2016) 
Çalışma kapsamında incelenen araştırmalarda göze çarpan bir diğer konu ise nanoteknoloji ile üretilen malzemelerin tanıtımı üzerine olmuştur. Bu konu üzerine yapılan etkinliklerin özellikleri Tablo 5'te sunulmuştur.

Tablo 5. Nano Malzemeler Üzerine Yapılan Etkinlikler

\begin{tabular}{|c|c|c|c|}
\hline Etkinlik & Türü & Örneklem Düzeyi & Makale Kodları \\
\hline \multirow{2}{*}{ LED lambalar } & \multirow{2}{*}{ Deney } & Lise & M4 \\
\hline & & Öğretmen & M5 \\
\hline \multirow{3}{*}{ Ferro sivilar } & \multirow{3}{*}{ Deney } & Ortaokul & M12 \\
\hline & & Üniversite & M19 \\
\hline & & Öğretmen & M17 \\
\hline \multirow{2}{*}{$\begin{array}{l}\text { Gümüş ve Altın nano } \\
\text { parçacıklar }\end{array}$} & Deney & Ortaokul & M18 \\
\hline & Deney & Lise & M9 \\
\hline $\begin{array}{l}\text { Fulleren ve karbon } \\
\text { nanotüp }\end{array}$ & Modelleme & Lise & M6 \\
\hline
\end{tabular}

Tablo 5 incelendiğinde farklı örneklem gruplarına yönelik nano malzemeler ile yapılan deneysel etkinliklerin bulunduğu görülmektedir. LED lambalardaki nano özellikleri anlamaya yönelik deneysel etkinlikler, nanoparçacık içeren ferro sıvıların mıknatıs ile etkileşiminin gösterildiği deneyler, gümüş nano parçacıkların antibakteriyel etkisini gözlemleme ve nano boyuta inildiğinde altın parçacıklarının renk değişimini gözlemleme incelenen araştırmalarda tespit edilen etkinlikler olmuştur. Ayrıca karbon nanotüpleri modelleyerek öğretmeye yönelik çalışma da bulunmaktadır. Şekil 5'te karbon nanotüp örnekleri görülmektedir.
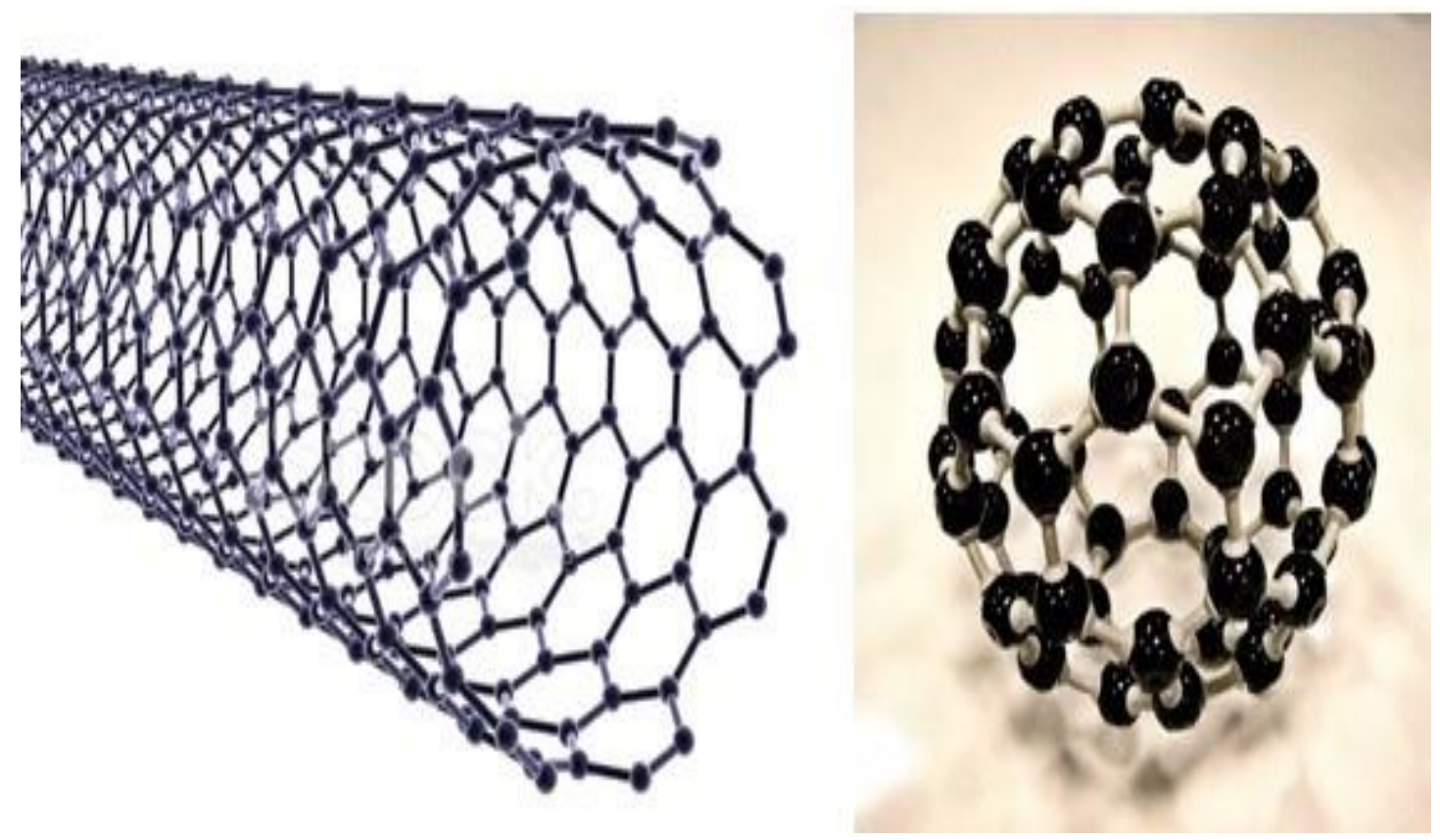

Şekil 5. Karbon Nanotüp (solda) ve Fulleren Modeli (sağda) (The NISE Network, 2016)

Bazı NBT öğretimi çalışmalarında nanoteknolojinin topluma fayda ve zararlarının konu edildiği nanoetik temasının işlendiği tespit edilmiştir. Nanoetik konusunun işlendiği çalışmaların özellikleri Tablo 6'da görülmektedir. 
Tablo 6. Nanoetik Üzerine Yapılan Etkinlikler

\begin{tabular}{llll}
\hline Etkinlik & Türü & Örneklem Düzeyi & Makale Kodlar1 \\
\hline \multirow{2}{*}{$\begin{array}{l}\text { Nanoteknolojinin fayda ve } \\
\text { zararları }\end{array}$} & \multirow{2}{*}{\begin{tabular}{lll} 
Tartışma \\
\cline { 3 - 4 }
\end{tabular}} & Ortaokul & M12, M18 \\
\cline { 3 - 4 } & & Üniversite & M9 \\
\cline { 3 - 4 } & Öğretmen & M16, M5 \\
\hline \multirow{2}{*}{\begin{tabular}{l} 
Uzmanlar ile görüşme \\
\cline { 3 - 4 }
\end{tabular}} & Mülakat & Ortaokul & M12, M18 \\
\cline { 3 - 4 } & & Öğretmen & M16 \\
\hline
\end{tabular}

Tablo 6 incelendiğinde nanoteknolojinin fayda ve zararlarının öğrenciler arasında tartışma yöntemi ile sorgulandığı ve nanoteknoloji uzmanlarıla mülakat yapılarak nanoetik boyutunun incelendiği çalışmalar görülmektedir.

Son olarak incelenen araştırmaların bazılarında NBT öğretimi çalışmalarının sonunda katılımcı gruplardan nano ürün tasarlamaları istenmiş ve geliştirlen nanoteknolojiye yönelik tanıtıcı resimler, nanorobot tasarımları, AFM/STM modelleri gibi metaryeller kapanış programında sergilenmiştir.Ayrıca bu kapsamdaki çoğu çalışmanın başlangıcında katılımcılara nanoteknolojiyi genel hatları ile tanıtan video ve görsel sunumlarla giriş yapıldığ 1 ve M14 kodlu çalışmada ise NBT de gerekli olan temel kavramların bir grup fen bilimleri öğretmenlerine çevrimiçi olarak tanıtıldığı tespit edilmiştir.

\section{TARTIŞMA, SONUÇ VE ÖNERILER}

Tematik analizi yapılan çalışmalarının en temel konusu nano ölçeğin öğrencilere öğretilmesi olmuştur. "Büyük fikirler"de boyut/ölçek kavramı olarak yer alan (Stevens ve diğerleri, 2009) nano parçacıkların büyüklüğünü kavramsallaştırmaya yarayacak bu konu için öncelikle nano ölçeğin iyi anlaşılması gereklidir. Araştırma kapsamında incelenen deneysel çalışmalarda ilk olarak öğretilmeye çalışılan kavram nanometre ölçüsünün anlaşılmasına yönelik olan nanoölçek (nanoskala) olmuştur. Bunun için bazı çalışmalar görsel resim ve videolar kullanmıştır. "Power of tens" gibi videolar ve nanoskalayı görselleyen resimlerden yararlanılmıştır. İnsanların çıplak gözle göremedikleri çok küçük şeyleri anlamlandırmak için görselleştirmeyi kullanmak, öğrencilerin kavramları daha derinlemesine anlamalarına yardımcı olur. Video ve görsel resimlerle giriş yapılan konunun pekişmesi için en etkili yollardan biri kavramı pekiştiren etkinliklerdir. İncelenen çalışmalarda ölçek kavramını anlamlandıracak "kağıt kesme" aktivitesi görülmektedir. Öğrencilere verilen bir kağıt parçasını nano metre seviyesine gelene kadar makasla ortadan ikiye ayırmaları ve bu işlem için düşünmeye sevk eden hesaplamalar yapmaları istenmiştir. Böylece öğrenciler, nano ölçeğin ne kadar küçük olduğunu ve nano ölçekte çalışmak için farklı özel araçlara ihtiyaç duyulacağını anlayabilirler. Yine nano ölçeği pekiştirecek ve öğrencilerin nano ölçekteki maddeleri tanımalarını pratikleştirecek nesneleri boyutuna göre sıralama etkinliği yaptırılmıştır. Virüsten, futbol sahasına, DNA'dan bakteriye farklı boyutlardaki nesnelerin bulunduğu kartları boyuta göre büyükten küçüğe doğru sıralama ya da nanoskaladaki yerine yerleştirme oyunları ile öğrencilerin nano ölçeğe aşinalığ artabilir. Bu şekilde öğrenciler mikro ölçekten nano ölçeğe kadar çeşitli nesneleri keşfederek nano ölçeği görselleştirmiş olurlar. Ek olarak 'The scale of the Universe' yazılım uygulamasını (http://htwins.net/scale2), kullanan çalışmalarda mevcuttur (Mandrikas ve diğerleri, 2020). Aktiviteler öğrencilerin nano ölçekteki nesnelerin boyutunu belirleyerek diğer ölçeklerdeki nesnelerle karşılaştırma firsatı sunar. Bu şekilde öğrenciler nanometrenin ne kadar küçük olduğunu kavrayabilirler. 
Maddelerin özellikleri, boyuta bağl1 olarak değişebilir ve nanoboyuta inildikçe, beklenmedik farklı özellikler gösterebilir (Stevens ve diğerleri, 2009). Cisimler yığın halden nanoboyuta yaklaştıkça yüzeydeki atom sayısı önemli ölçüde artar. Yüzey atomları çevre ile etkileşime girdiğinden, yüzeydeki atom sayısı oranı kimyasal reaktiviteyi önemli ölçüde etkiler. Maddeler nanopartiküllere dönüştükçe yüzey alanı/hacim oranı büyük oranda artacak ve malzemenin reaktivitesi o oranda yükselecektir (Stevens ve diğerleri, 2009). İncelenen araştırmalarda öğrencilere öğretilmeye çalışılan önemli kavramlardan biri maddelerin küçüldükçe yüzey alanı/hacim oranındaki artışı göstermeye çalışmak olmuştur. Bunun için iki önemli etkinlik kullanılmıştır. Birincisi belli bir boyutta küpü (macar küpü veya agar küpü gibi), her seferinde daha küçük eşit küplere bölerek yüzey alanı/hacim oranlarını hesaplama ve sonuçları karşılaştırma etkinliğidir. Şekil 2'de görüldüğü gibi hesaplama yapan öğrenciler küp küçüldükçe yüzey alanı/hacim oranın arttığını matematiksel olarak göreceklerdir. Böylece öğrenciler, nesnelerin küçüldükçe çevresi ile daha fazla maruz kalacağı bununda fiziksel ve kimyasal aktivitesini değiştireceğini fark etmiş olur. Yine nano parçacıkların makro düzeydeki hallerinden farklı davranmasının boyuta bağlı özelliklerden kaynaklandığını göstermeye yarayan bir aktivite olarak reaksiyon hızı deneyleri, incelenen çalışmalarda sıklıkla kullanılmıştır. Öğrencilere aynı miktar maddenin tek parça halinde ve yüzey alanı artırılmış küçük taneler halinde reaksiyonunu gözleme firsatı sunulmuştur. Bunun için bazı çalışmalar efervesan tabletin tek parça halinde suda çözünmesi ile ince toz haline getirilmiş halinin suda çözünme sürecini öğrencilere etkinlik olarak kullanmıştırlar. Bazı çalışmalarda etkinlik olarak, büyük parça halinde patates ile aynı miktarda küçük parçalar halindeki patateslerin hidrojen peoksit ile reaksiyonu deneyini kullanılmıştır. Adadan ve diğerlerinin (2017) yaptıkları çalışmada ise eşit büyüklükte üç agar küp kullanılarak biri tam halde, ikincisi 4 eşit parçaya, üçüncüsü 8 eşit parçaya bölünür. Agar küpleri önce seyreltik $\mathrm{NaOH}$ ve fenolftalein ile muamele edilerek bazik ve pembe renkli olmaları sağlanır. Daha sonra seyreltik $\mathrm{HCl}$ çözelisi bulunan üç farklı kaba konur. Ardından nötrleştirme reaksiyonu neticesinde küplerin yüzeylerinden başlayarak renk solması gözlenir. Öğrenciler renk kaybolma sürelerini not ederek yüzey alanı/hacim oranının reaksiyon hızına etkisini gözlemlerler. Deneysel etkinlikler öğrencilerin sorgulama yapmalarına ve kalıcı öğrenme gerçekleştirmelerine yol açar. NBT öğretiminde deneysel etkinliklere s1k s1k yer verilmiştir. Lati, Triampo ve Yodyingyong (2019) ise silika aerojel hazırlama aktivitesi ile nano boyutun etkisini anlatmaya çalışmıştır. \% 95 havadan oluşan silika aerojel yüksek özgül yüzey alanı gibi olağanüstü özelliklere sahiptir. Benzer şekilde tek kullanımlık çocuk bezleri süper emici polimer jellerden oluşur ve ağırlığından onlarca kat daha fazla sıvı emmelerini sağlar. Bu emme yeteneği, malzemenin yüzey alanı/hacim oranını artıran gözenekli bir yapıdan kaynaklanır (Stevens ve diğerleri, 2009).

Nanobilimin ortaya çıkışı ve gelişmesi, nano boyutta görüntüleme ve işlem yapmaya yarayan nano duyarlı aletlerin geliştirilmesi ile başlamıştır. Nano nesneler günlük hayatta gözle göremediğimiz boyutta olduğundan karekterizasyon için özel araçlara ihtiyaç duyulur. AFM, bilim insanlarının maddeleri atomik seviyeye kadar gözlemlemelerini ve manipüle etmelerini sağlayan teknik bir araştırma cihazıdır. STM, ölçüm probu ile numune tanecikleri arasındaki etkileşimlerden yararlanarak, yüzey atomlarını bir 1sı haritası olarak resmedebilir (Hingant ve Albe, 2010). AFM veya STM gibi cihazların tanıtılması, lise ve üniversite öğrencilerinin NBT öğretim çalışmalarında önemli bir yeri vardır. Tematik analizi yapılan çalışmalarda üçüncü sırada öne çıkan konu AFM ve STM gibi nano duyarlı aletlerin tanıtılması olmuştur. Buna yönelik yapılan etkinliklerin başında AFM'nin modellenmesi gelmektedir. Şekil 3 de görüldüğü gibi AFM'yi; dirseği, bu dirseğe bağlı ince ucu, ışın sapmasını yakalayan lazeri ve taradığ 1 yüzeyi görselleştirerek modelleyen çalışmalar bulunmaktadır (Blonder ve Sakhnini, 2012). Johnstone'nun, (2000) kimya eğitimi için birbirine bağlanmasını önerdiği; makro seviye, mikro seviye ve temsil seviyesini, çok küçük şeyleri inceleyen NBT öğretimi içinde kullanmak faydalı olacaktır. AFM gibi son teknoloji teknikler, makro ve alt mikro düzeyler arasında bir bağlantı kurar (Blonder, 2010). Bu bağlantı öğretimde simülasyonlar ve modellemeler kullanılarak sağlanabilir. Bazı çalışmalarda ise STM cihazının nasıl çalıştığını göstermek için "kara kutu" 
modellemesi tercih edilmiştir. Bu etkinlikte öğrencilere tabanına farklı boyutlarda nesneler yapıştırılmış kapalı bir karton kutu verilir. Kutunun üstüne küçük birkaç delik açılır. Öğrencilere plastik çubuk, tahta kalem, metal şiş gibi çeşitli araçlar verilir ve bu araçları kullanarak kapalı kutunun içindeki nesnelerin boyutlarını grafik olarak resmetmeleri istenir. Bu etkinlik ile öğrenciler STM mikroskobunun çalışma prensibini daha iyi kavrayacaktır. Birkaç araştırmada öğrenciler nanobilim araştırma merkezlerine götürülerek orada gerçek AFM ve STM cihazları uzmanları tarafından tanıtılmış (Blonder, 2011; Blonder ve Mamlok Naaman, 2016; Sgouros ve Stavrou, 2019), bir kaçında ise öğrenciler AFM ve STM cihazlarını kullanma firsatı bulmuştur. Öğrencilerin, nanoteknoloji araştırma merkezlerini ziyaret ederek bu cihazların asıllarını görmeleri, kullanmaları ve uzmanlar tarafından bilgilendirilmeleri motivasyonlarını artıracak ve nanoteknolojiye karşı olumlu tutumlar geliştirmelerini sağlayacaktır.

Doğadaki bulunan yapılarda atom ve moleküller kimyasal ve fiziksel bağlarla kendi kendini tamamlayan bir bütün halinde bulunur. Kendi kendine montaj diye isimlendirilen bu doğal yapılar taklit edilerek laboratuvar ortamında istenilen özelliklere uygun nano boyutlu yapılar elde edilebilir (Stevens ve diğerleri, 2009). Tematik analizi yapılan çalışmalarda kendi kendine montaj (self-assembly) kavramına yönelik nanoteknoloji uygulamalarını tanıtıcı etkinlikler tespit edilmiştir. Bu amaçla en çok doğadaki lotus bitkisinin yaprağını örnek alan ve "lotus etkisi" olarak ifade edilen etkinlik görülmektedir. Şekil 4'de görüen lotus bitkisi yaprağı doğal olarak nano boyutta hidrofob bir yapı ile kaplıdır. Yapılan deneysel etkinliklerle de görülebilecek şekilde lotus bitkisine damlatılan su damlacıkları yaprağın yüzeyinde tutunamayarak 180 dereceye yakın bir açı ile yüzeyden kayar. Bu şekilde yüzeyden kayan su damlacıkları aynı zamanda yaprak yüzeyindeki toz ve kirleri de temizleyerek yüzeyden ayrılır. NBT öğretim çalışmalarında öğrencilere lotus bitkisine su damlatma etkinliği ve nano yüzeyle kaplanmış 1slanmayan tekstil gibi ürünlerinin gösterildiği benzer çalışmalar yapılabilir. Bunlar öğrencilerin nano ürünlerin ardındaki bilimsel altyapıyı ve teknolojiye dönüşümünü fark etmeleri ve bu alana ilgi duymalarını sağlayacaktır. Lotus etkisi gibi kendi kendini temizleyen yüzeylerin video görselleri ile konu desteklenebilir. Örnek olarak Titanyum dioksit $\left(\mathrm{TiO}_{2}\right)$ ile kaplı yüzeylerin kendini temizleyebilmesi kullanılabilir. $\mathrm{TiO}_{2}$ ile kaplı yüzeylerin güneş ışınları vurduğunda foto katalizlenme ile yüzeyle temas eden havadaki su molekülleri oksijen radikallerine ayrıştırabilmekte ve sonrasında radikallere temas eden organik kirlilik içeren moleküller su, karbon dioksit, mineral tuzlara dönüştürebilmektedir. Kendi kendini temizleyen elbiseler, camlar gibi nano ürünler öğretim çalışmalarında kullanılabilir. Blonder (2011), yaptı̆̆ çalışmaya katılan yüksek lisans öğrencilerinden nanobilimin elektronik, optik, mekanik, enerji ve manyetizmadaki farklı uygulamalarından bir konuyu seçerek sunum hazırlamaları istenmiştir. Bu şekilde öğrencilerin nano uygulamaları tanımları sağlanmıştır. Benzer konuda beş nanoteknoloji uygulamasını (nanotıp, nanoelektronik, fotovoltaik hücreler, nanobotlar ve kendi kendini temizleme) okullarda öğretmek için bağlam oluşturmaya yönelik uzmanlar topluluğunun fikir birliğine varma (delphi yöntemi) çalışması ise Sakhnini ve Blonder (2016) tarafından yapılmıştır. Bu çalışmada NBT öğretiminin "Büyük Fikirler" deki yedi temel kavrama dayandığ 1 tespit edilmiştir. Nano uygulamaları öğrencilere daha iyi tanıtmak için nano araştırma merkezlerine ziyaret, video izleme gibi etkinliklerde bulunmaktadır. Blonder ve Mamlok Naaman (2016) öğrencileri nano araştırma laboratuvarına götürerek kendinden montajlı tek tabakalar hakkında sorgulamaya dayalı öğrenmelerine yönelik etkinlik yapmıştırlar. Stavrou ve diğerleri (2018) araştırma laboratuvarında yeni geliştirilmiş kendi kendini temizleyen malzemelerle ilgili video izlettirmiştir. Lati ve diğerleri (2019) silika aerojel ile bir aktivite tasarlayarak öğrencilerin süper hidrofobikliği ve kendi kendini temizleyen yüzey kavramlarını anlamalarına yardımcı olmaya çalışmıştır. Okullarda kolay ulaşılabilir ve ekonomik olan etkinlikler seçilerek öğrencilere yaptırılabilir. Bu öğrencilerin nanoya ve bilime yönelik olumlu tutum geliştirmelerine yardımcı olacaktır.

Doğal yollardan oluşan nano malzemeler olduğu gibi endüsriyel olarak üretilen çeşitli nano malzemeler de vardır. Kompozitlerden üretilen hafif bisikletler, nanoyapılı katalizörler, transistörler, bilgisayar yongaları, pil ve günes panelleri, tv ve bilgisayar ekranları, güneş 
kremleri, nano yüzeyle kaplı tekstil ürünleri gibi günlük hayatımıza giren birçok nano malzeme bulunmaktadır. Tematik olarak incelenen NBT öğretim çalışmalarında öğrencilere nanomalzemeleri tanıtıcı etkinlikler yapıldığı görülmektedir. Işık yayan diyotlar'ın (LED) tanıtıldığı çalışmalarda nano ürün olan LED lambalar kullanılmıştır. Ferro sıvılara mıknatıs yaklaştırarak sıvı içerisindeki nano parçacıkların görsel olarak gösterildiği etkinlik çalışması da her seviyede öğrencilere yönelik yapılabilir. Sakhnini ve Blonder (2016) yaptıkları çalışmada nanotıp, nanoelektronik, fotovoltaik hücreler ve nanobotlar gibi nanoteknolojik malzemeleri bir bağlam temelinde öğretmeye çalışmıştır. İlk nano malzemelerden olan fulleren ve karbon nano tüpü tanıtmaya yönelik araştırmalarda tespit edilmiştir. 60 adet karbon atomundan (C60) oluşan bir nano kütlenin futbol topuna benzer şekilde bir araya geldiği nano malzemeye fulleren adı verilmiştir. Şekil 5'te görüldüğü gibi tek sıra halinde içi boş tüp seklinde halka oluşturarak karbon atomlarının bir araya gelmesi karbon nanotüpleri oluşturur. Karbon nanotüpler hafif, esnek ve çok dayanıklı olmasının yanında iletkenliği de diğer nano olmayan malzemelere göre çok daha iyi olması nedeni ile üzerinde çalışılması ve tanıtılmasını gerektiren bir nano malzemedir. Kampschulte, Akaygün, Adadan, Eilert ve Heyduck (2017) ise yaptıkları çalışma etkinliğinde öğrencilere gümüş nano parçacık sentezleterek anti bakteriyel etkisini gözlemleme firsatı verilmiştirler.

Çoğu teknolojik yeniliklerde olduğu gibi nanoteknolojide günlük hayatımızı olumlu ve olumsuz etkileyebilecek potansiyel barındırmaktadır. Toplumun bu konuda bilinçlendirilmesi gerekir. Nanoteknolojinin topluma sağlayacağ 1 yararlara ve neden olacağ bilinçli insanlar yetiştirmek nano eğitimcilerin görevidir (Wansom ve diğerleri, 2009). Tematik analizi yapılan çalışmalarda en sık işlenen konulardan biri de nano teknolojinin topluma fayda ve zararlarının tartışıldığı nano etik konusu olmuştur. Nanoteknoloji üzerine gazete haberlerinin ve makalelerin okunup öğrenciler arasında bireysel ve grup tartışmalarının yapıldığ etkinliklerin bulunduğu görülmektedir. Bazı çalışmalarda ise nanoteknolojinin etik unsurlarına yönelik bilim inanları ve nanobilim uzmanları ile mülakat yapılmıştır. Nanoteknolojinin yeni gelişmekte olan bir alan olması nedeniyle nano partiküllerin hayatımızı nasıl etkileyeceğine yönelik sahip olduğumuz bilgiler sınırlıdır. Bu anlamda nanoteknolijinin zararları henüz tam olarak tespit edilememiş olabilir. Ancak atıklara karışan nano parçacıkların canlılar için bir risk oluşturacağı öngörülebilir. Bunun için nano teknolojinin avantajları ve beklenen riskler farklı eğitim düzeylerine entegre edilerek öğrencileri bilinçlendirmek gerekmektedir.

Bazı öğretim çalışmalarının sonunda katılımcılardan nanoteknolojiye yönelik fikir geliştirmeleri istenmiş ve buna yönelik düşüncelerini yansıtan model, resim, yansıtıcı günlük gibi tasarım çalışması yaptırılmıştır. Daha sonra etkinliklerin son günü bu tasarımlardan sergi hazırlamaları sağlanmıştır. Öğrencilerin hayal güçlerinin gelişmesini teşvik edecek bu tür çalışmalar katılımcıların ürün oluşturma becerilerini de geliştirecektir.

Uluslararası literatür 1şığında NBT öğretiminin nasıl yapıldığına yönelik yapılan inceleme sonucunda; ABD Ulusal Bilim Vakfi'nın desteği ile Stevens ve diğerlerinin (2009) "büyük fikirler" adıyla ortaya koyduğu temel konuların öğrencilere öğretilmeye çalışıldığ görülmektedir. İncelenen çalışmalarda altı temanın öne çıktığı gözlenmektedir. Bunlar: boyut/ölçek, boyuta bağlı değişen özellikler, nanoteknolojide kullanılan araçlar, nanoteknolojide uygulamalar, nano malzemeler, nanoteknolojinin fayda ve riskleri. Bu çalışmanın sonuçlarına benzer şekilde Ghattas ve Carver (2012) yaptıkları literatür derleme çalışmasında bazı temaların öne çıktığı rapor edilmiştir. Bunlar, nanoteknolojinin kökenleri, okul etkinlikleri, tüketici ürünleri, mühendislik uygulamaları, etik konular ve nanoteknolojinin etkileridir. Nanometreyi öğrencilerin kavraması için boyut ve ölçek kavramı altında multimedya görselleri, cisimlerin nanosklada yerini bulma etkinliği ve kağıt parçasını nano boyuta indirgeyene kadar kesmeye çalışma etkinlikleri yapılmıştır. Maddelerin nano boyuttaki davranış değişikliğini açıklamaya yönelik olarak; yüzey alanı/hacim hesapları yapma etkinlikleri ve maddelerin tek parça boyutları ile aynı miktarda küçük parçalar halindeki reaksiyon aktivitelerine yönelik deney yapıldığ görülmektedir. Öğretim çalışmalarında nanoteknoloji çalışmalarında kullanılan görüntüleme ve 
karakterizasyon araçları öğrencilere tanıtılmaya çalışılmıştır. Bu kapsamda nano araştırma merkezlerine öğrenciler götürülerek orada bu araçlar uzmanlarınca tanıtılmıştır. Ayrıca nano duyarlı aletlerden AFM ve STM'nin modelleme etkinlikleri ile çalışma prensipleri açıklanmaya çalışılmıştır. Öğrencilerin nanoteknolojik ürünlerin oluşturulmasında yatan bilimsel altyapıyı anlamaları için doğadaki nano yapılar gösterilmiştir. Lotus bitkisinin hidrofob yüzeyi etkinlikler ile gösterilerek bu yapının taklit edilmesiyle üretilen nano ürünler ve uygulamalar öğretim çalışmalarında kullanılmıştır. Benzer aktiviteler ile kendi kendini temizleyen nano ürünler, LED lambalar, ferro sıvılar ile nano malzemeler öğrencilere öğretilmeye çalıșılmıştır. İncelenen NBT öğretim çalışmalarında etkinliklerin son oturumu genellikle nanoteknolijinin fayda ve risklerinin tartışılmasına ve nano ürün tasarlanmaya çalışmasına ayrıldığı tespit edilmiştir.

Nanobilim ve nanoteknolojiyi eğitime entegre etme hususunda zorluklardan biri öğrencilerin seviyelerine uygun konuların seçilmesidir. Burada disiplinler arası bir yaklaşıma ihtiyaç duyulmaktadır (Jones ve diğerleri, 2013). Nanoteknolojiyi öğrenmek için en uygun seviyenin lise düzeyi olduğu görülmektedir. İncelenen araştırmalarda yapılan etkinliklerin büyük bir kısmı lise düzeyi öğretmen ve öğrencilerine yönelik olduğu tespit edilmiştir. Bunun yanında lisans düzeyi öğrencilere yönelik çalışmalar ve öğretmen eğitimi için yürütülen çalışmaların da bulunduğu görülmektedir. Az sayıda da olsa ilköğretim öğrencilerine yönelik yapılmış çalışmalar da bulunmaktadır. Günümüzde nanobilim ve nanoteknoloji, hızla gelişen popüler bir bilim alanı olmuştur. Kullandığımız nano ürünler hakkında bilgi sahibi olmak ve nanoteknoloji rekabetinde yer alacak bilim insanlarını yetiştirmek için nanoeğitimin yaygınlaşmasına ihtiyaç vardır. $\mathrm{Bu}$ ihtiyaç nedeniyle, farklı eğitim seviyelerindeki öğrencilerin nanoteknoloji ile ilgili temel bilgilerle tanışmaları gerekmektedir. Dünyada ilk önce lisansüstü düzeyde başlayan nanoeğitim daha sonra lisans düzeyine yayılmıştır. Ülkemizde birkaç üniversitede (Sivas Cumhuriyet Üniversitesi, TOBB Ekonomi ve Teknoloji Üniversitesi, Yeditepe Üniversitesi, Burdur Mehmet Akif Ersoy Üniversitesi) lisans düzeyinde nanoeğitim yapılmaktadır. Ancak lise düzeyinde henüz nanoeğitim verildiği söylenemez. NBT öğretiminde "büyük fikirler" 1şı̆̆ında okul müfredatlarına nano kavramların girmesi gerektiği söylenebilir. Burada karşımıza çıkan başka bir zorluk ise öğretmenlerin genellikle tek bir alanda uzmanlaşmış olmasıdır (Drane ve diğerleri, 2009). Eğitimlerini nanobilimin gelişmesinden önce tamamlamış olan öğretmenler yabancısı oldukları bu konuları anlatmakta isteksiz davranacakları ve zorlanacakları düşünülebilir. Bu nedenle öğretmenler yaz kampları gibi hizmetiçi eğitim etkinlikleri ile nanobilim ve teknoloji konularında eğitimden geçirilmelidir. Lisans düzeyinde öğretmenlik eğitimi veren eğitim fakülteleri fen ve matematik alanları programlarına nanoteknolojide temel kavramları eklemeli ve yeni mezun olacak öğretmen adayları nanoteknoloji alanında donanımlı bir şekilde mezun olmaları, mesleğe başladıktan sonra nanoeğitim konusunda fayda sağlayacakdır. Okullarda fizik, kimya, biyoloji ve matematik derslerinde uygun bağlamlara nanoteknoloji konuları eklenebileceği gibi seçmeli tek bir bilim teknoloji gibi ders içinde de bu eğitim verilmesi sağlanabilir. Etkinlikler aracılığıyla kazanılan deneyimler NBT öğrenimini daha etkili kılar (Furlan, 2009). Bu sebeple NBT konularına yönelik öğretimin, uygulamalı bir şekilde, etkinliklerle gerçekleştirilmesi, aktif öğrenme anlayışlarına uygun şekilde kalıcı öğrenmenin gerçekleşmesini sağlayacaktır. Yapılan çalışmanın nanoeğitim ile ilgilenen araştırmacılara, FeTeMM (STEM) çalışmalarına, fen ve matematik müfredatı çalışmalarına, fen ve teknoloji, fizik, kimya, biyoloji ve matematik öğretmenlerine ve eğitim yöneticilerine katkı sağlayacağı düşünülmektedir.

\section{KAYNAKÇA}

Adadan, E., Akaygun, S., \& Sanyal, A. (2017). Size-dependent properties of matter: Is the size of a pill important?. Science Activities, 54(3-4), 86-95.

Alpat, S. K., Uyulgan, M. A., Şeker, S., Altaş, H. Ş. ve Gezer, E. (2017). Nanoteknoloji konusunda işbirlikli öğrenme yönteminin ortaöğretim 10. sınıf öğrencilerinin akademik başarı ve görüşlerine etkisi. İnönü Üniversitesi Eğitim Fakültesi Dergisi, 18(1), 27-57. 
Blonder, R. (2010) The influence of a teaching model in nanotechnology on chemistry teachers' knowledge and their teaching attitudes. Journal of Nano Education 2, 67-75. https://doi.org/10.1166/jne.2010.1004

Blonder, R. (2011). The story of nanomaterials in modern technology: An advanced course for chemistry teachers. Journal of Chemical Education, 88(1), 49-52.

Blonder, R., \& Dinur, M. (2011). Teaching nanotechnology using student-centered pedagogy for increasing students' continuing motivation. Journal of Nano Education, 3(1-2), 51-61.

Blonder, R., \& Mamlok Naaman, R. (2016). Learning about teaching the extracurricular topic of nanotechnology as a vehicle for achieving a sustainable change in science education. International Journal of Science and Mathematics Education, 14(3), 345-372.

Blonder, R., \& Sakhnini, S. (2012). Teaching two basic nanotechnology concepts in secondary school by using a variety of teaching methods. Chemistry Education Research and Practice, 13(4), 500-516. https://doi.org/10.1166/jne.2011.1016

Blonder, R., \& Sakhnini, S. (2017). Finding the connections between a high-school chemistry curriculum and nano-scale science and technology. Chemistry Education Research and Practice, 18(4), 903-922.

Çalık, M. ve Sözbilir, M. (2014). İçerik analizinin parametreleri. Eğitim ve Bilim, 39(174), 33-38.

Demircioğlu, H. ve Özdemir, R. (2019). Bağlam temelli öğrenme yaklaşımının öğretmen adaylarının nanoteknoloji konusunu anlamaları üzerindeki etkisi. Journal of Computer and Education Research, 7(14), 314-336.

Denkbaş, E. B. (2015). Nanoteknolojiye yapılacak yatırımlar, ülkelerin ekonomik gücünü yansitabilecek bir parametre olacak. Bilişim Dergisi, (41), 154, 78-87.

Drane, D., Swarat, S., Light, G., Hersam, M., \& Mason, T. (2009). An evaluation of the efficacy and transferability of a nanoscience module. Journal of Nano Education, 1(1), 8-14.

Erkoç, Ş. (2007). Nanobilim ve nanoteknoloji (2. Bak1). Ankara: Odtü Yayıncılık.

Furlan, P. Y. (2009). Engaging students in early exploration of nanoscience topics using handson activities and scanning tunneling microscopy. Journal of Chemical Education, 86(6), 705-711.

Gardner, G., Jones, M. G., \& Falvo, M. (2009). " New science" and societal issues. The Science Teacher, 76(7), 49.

Ghattas, N. I., \& Carver, J. S. (2012). Integrating nanotechnology into school education: A review of the literature. Research in Science \& Technological Education, 30(3), 271-284.

Gilbert, J. K., \& Lin, H. S. (2013). How might adults learn about new science and technology? The case of nanoscience and nanotechnology. International Journal of Science Education, Part B, 3(3), 267-292.

Gül, Ş. ve Sözbilir, M. (2015). Fen ve matematik eğitimi alanında gerçekleştirilen ölçek geliştirme araştırmalarına yönelik tematik içerik analizi. Eğitim ve Bilim, 40(178), 85-102.

Healy, N. (2009). Why nano education?. Journal of Nano Education, 1(1), 6-7.

Hingant, B., \& Albe, V. (2010). Nanosciences and nanotechnologies learning and teaching in secondary education: A review of literature. Studies in Science Education, 46(2), 121-152.

Jackman, J. A., Cho, D. J., Lee, J., Chen, J. M., Besenbacher, F., Bonnell, D. A., et al. (2016). Nanotechnology education for the global world: Training the leaders of tomorrow. ACS Nano, 10, 5595-5599. 
Jones, M. G., Blonder, R., Gardner, G. E., Albe, V., Falvo, M., \& Chevrier, J. (2013). Nanotechnology and nanoscale science: Educational challenges. International Journal of Science Education, 35(9), 1490-1512.

Johnstone, A. H. (2000). Teaching of chemistry-logical or psychological?. Chemistry Education Research and Practice, 1(1), 9-15.

Kampschulte, L., Akaygün, S., Adadan, E., Eilert, K., \& Heyduck, B. (2018). Interdisciplinary research brought to school-connecting chemistry and biology through nanotechnology. Journal of Microbiology Biology Education, 19(1), 1-3.

Kulik, T., \& Fidelus, J. D. (2007). Education in the field of nanoscience. European Nanotechnology Gateway Warsaw.

Lati, W., Triampo, D., \& Yodyingyong, S. (2019). Exposure to nanoscience and nanotechnology using guided-inquiry-based activities with silica aerogel to promote high school students' motivation. Journal of Chemical Education, 96(6), 1109-1116.

Lin, S. Y., Wu, M. T., Cho, Y. I., \& Chen, H. H. (2015). The effectiveness of a popular science promotion program on nanotechnology for elementary school students in I-Lan City. Research in Science \& Technological Education, 33(1), 22-37.

Mallmann, M. (2008). Nanotechnology in School. Science in School 10, 70-75.

Mandrikas, A., Michailidi, E., \& Stavrou, D. (2020). Teaching nanotechnology in primary education. Research in Science \& Technological Education, 38(4), 377-395.

Murday, J. S. (2009). NSF workshop report: Partnership for nanotechnology education. University of South California, Los Angeles.

Nanosense Project. (2007). Size matters:Introduction to nanoscience. Retrived from https://nanosense.sri.com/

Nanoyou Project. (2016). Nano for youth is a project funded by the european commission's seventh framework programme. Retrived from https://nanoyou.eu/

Nikalje, A. P. (2015). Nanotechnology and its applications in medicine. Med Chem, 5(2), 81-89.

Planinšič, G., \& Kovač, J. (2008). Nano goes to school: A teaching model of the atomic force microscope. Physics Education, 43(1), 37.

Roco, M. C. (2003). Broader social issues of nanotechnology. Journal of Nanoparticle Research, $5,181-189$.

Roco, M. C., Mirkin, C. A., \& Hersam, M. C. (2011). Nanotechnology research directions for societal needs in 2020: Retrospective and outlook (Vol. 1). Springer Science \& Business Media.

Roco, M. C. (2018). Overview: Affirmation of nanotechnology between 2000 and 2030. Chapter 1. In T. Mensah, B. Wang, G. Bothun, J. Winter \& V. Davis (Ed.), Frontiers of nanotechnology: Nanotechnology commercialization (pp. 1-23). Wiley Publ.

Sagun Gököz, B. (2012) Design and implementation of a nanoscience \& nanotechnology workshop: Investigating 11th grade students' awareness and conceptual understanding of nanoscience \& nanotechnology. (Unpublished Master Thesis). Boğaziçi University. İstanbul, Turkey.

Sagun Gököz, B. ve Akaygün, S. (2013). Üniversiteden liseye uzanan köprü: Bir nanobilim atölye çalışması. Boğaziçi Üniversitesi Eğitim Dergisi, 31(2), 49-72.

Sakhnini, S., \& Blonder, R. (2016). Nanotechnology applications as a context for teaching the essential concepts of NST. International Journal of Science Education, 38(3), 521-538. 
Sakhnini, S., \& Blonder, R. (2018). Insertion points of the essential nanoscale science and technology (NST) concepts in the Israeli middle school science and technology curriculum. Nanotechnology Reviews, 7(5), 373-391.

Schank, P., Krajcik, J., \& Yunker, M. (2007). Can nanoscience be a catalyst for educational reform. Nanoethics: The ethical and social implications of nanotechnology, 277-290.

Schwarzer, S., Akaygun, S., Sagun Gokoz, B., Anderson, S., \& Blonder, R. (2015). Using atomic force microscopy in out-of-school settings - two case studies investigating the knowledge and understanding of high school students. Journal of Nano Education, 7(1), 10-27.

Sgouros, G., \& Stavrou, D. (2019). Teachers' professional development in nanoscience and nanotechnology in the context of a community of learners. International Journal of Science Education, 41(15), 2070-2093.

Stavrou, D., Michailidi, E., \& Sgouros, G. (2018). Development and dissemination of a teaching learning sequence on nanoscience and nanotechnology in a context of communities of learners. Chemistry Education Research and Practice, 19(4), 1065-1080.

Stavrou, D., Michailidi, E., Sgouros, G., \& Dimitriadi, K. (2015). Teaching high-school students nanoscience and nanotechnology. LUMAT: International Journal on Math, Science and Technology Education, 3(4), 501-511.

Stevens, S., Sutherland, L., Schank, P., \& Krajcik, J. (2009) The big ideas of nanoscience: A guidebook for secondary teachers. NSTA Press, Arlington.

Şenel Zor, T. (2017). Etkinlik temelli nanobilim ve nanoteknoloji eğitiminin fen bilimleri ögretmen adaylarının nanobilim ve nanoteknoloji farkindalıklarına ve kavramsal anlayışlarına etkisi. (Yayınlanmamış Yüksek Lisans Tezi). Necmettin Erbakan Üniversitesi Eğitim Bilimleri Enstitüsü. Konya.

The NISE Network (2016). Nanodays collection. Ithaca, New York.

Wansom, S., Mason, T. O., Hersam, M. C., Drane, D., Light, G., Cormia, R., et al. (2009). A rubric for postsecondary degree programs in nanoscience and nanotechnology. International Journal of Engineering Education, 25, 615-627.

Zor, T. Ş. ve Aslan, O. (2018). The effect of activity-based nanoscience and nanotechnology education on pre-service science teachers' conceptual understanding. Journal of Nanoparticle Research, 20(3), 75.

\section{EKLER}

\section{Ek 1. Araştırma Kapsamında İncelenen Makaleler}

\begin{tabular}{ll}
\hline Kod & Makale Künyesi \\
\hline M1 & $\begin{array}{l}\text { Adadan, E., Akaygun, S., \& Sanyal, A. (2017). Size-dependent properties of } \\
\text { matter: Is the size of a pill important?. Science Activities, 54(3-4), 86-95. }\end{array}$ \\
M2 & $\begin{array}{l}\text { Blonder, R. (2010) The influence of a teaching model in nanotechnology on } \\
\text { chemistry teachers' knowledge and their teaching attitudes. Journal of Nano }\end{array}$ \\
& $\begin{array}{l}\text { Education 2, 67-75. https://doi.org/10.1166/jne.2010.1004 } \\
\text { Blonder, R. (2011). The story of nanomaterials in modern technology: An } \\
\text { advanced course for chemistry teachers. Journal of Chemical Education, 88(1), }\end{array}$ \\
49-52. & $\begin{array}{l}\text { Blonder, R., \& Dinur, M. (2011). Teaching nanotechnology using student- } \\
\text { centered pedagogy for increasing students' continuing motivation. Journal of } \\
\text { Nano Education, 3(1-2), 51-61. }\end{array}$ \\
\hline
\end{tabular}


M5 Blonder, R., \& Mamlok Naaman, R. (2016). Learning about teaching the extracurricular topic of nanotechnology as a vehicle for achieving a sustainable change in science education. International Journal of Science and Mathematics Education, 14(3), 345-372.

M6 Blonder, R., \& Sakhnini, S. (2012). Teaching two basic nanotechnology concepts in secondary school by using a variety of teaching methods. Chemistry Education Research and Practice, 13(4), 500-516. https://doi.org/10.1166/ jne.2011.1016

M7 Hingant, B., \& Albe, V. (2010). Nanosciences and nanotechnologies learning and teaching in secondary education: A review of literature. Studies in Science Education, 46(2), 121-152.

M8 Jackman, J. A., Cho, D. J., Lee, J., Chen, J. M., Besenbacher, F., Bonnell, D. A., et al. (2016). Nanotechnology education for the global world: Training the leaders of tomorrow. ACS Nano, 10, 5595-5599.

M9 Kampschulte, L., Akaygün, S., Adadan, E., Eilert, K., \& Heyduck, B. (2018). Interdisciplinary research brought to school-connecting chemistry and biology through nanotechnology. Journal of Microbiology Biology Education, 19(1), 13.

M10 Lati, W., Triampo, D., \& Yodyingyong, S. (2019). Exposure to nanoscience and nanotechnology using guided-inquiry-based activities with silica aerogel to promote high school students' motivation. Journal of Chemical Education, 96(6), 1109-1116.

M11 Lin, S. Y., Wu, M. T., Cho, Y. I., \& Chen, H. H. (2015). The effectiveness of a popular science promotion program on nanotechnology for elementary school students in I-Lan City. Research in Science \& Technological Education, 33(1), 22-37.

M12 Mandrikas, A., Michailidi, E., \& Stavrou, D. (2020). Teaching nanotechnology in primary education. Research in Science \& Technological Education, 38(4), 377-395.

M13 Sakhnini, S., \& Blonder, R. (2016). Nanotechnology applications as a context for teaching the essential concepts of NST. International Journal of Science Education, 38(3), 521-538.

M14 Sakhnini, S., \& Blonder, R. (2018). Insertion points of the essential nanoscale science and technology (NST) concepts in the Israeli middle school science and technology curriculum. Nanotechnology Reviews, 7(5), 373-391.

M15 Schwarzer, S., Akaygun, S., Sagun Gokoz, B., Anderson, S., \& Blonder, R. (2015). Using atomic force microscopy in out-of-school settings-two case studies investigating the knowledge and understanding of high school students. Journal of Nano Education, 7(1), 10-27.

M16 Sgouros, G., \& Stavrou, D. (2019). Teachers' professional development in nanoscience and nanotechnology in the context of a community of learners. International Journal of Science Education, 41(15), 2070-2093.

M17 Stavrou, D., Michailidi, E., \& Sgouros, G. (2018). Development and dissemination of a teaching learning sequence on nanoscience and nanotechnology in a context of communities of learners. Chemistry Education Research and Practice, 19(4), 1065-1080.

M18 Stavrou, D., Michailidi, E., Sgouros, G., \& Dimitriadi, K. (2015). Teaching highschool students nanoscience and nanotechnology. LUMAT: International Journal on Math, Science and Technology Education, 3(4), 501-511.

M19 Zor, T. Ş., \& Aslan, O. (2018). The effect of activity-based nanoscience and nanotechnology education on pre-service science teachers' conceptual understanding. Journal of Nanoparticle Research, 20(3), 75. 


\section{EXTENDED ABSTRACT}

The fast growing industry of Nanotechnology has paved the way for major investments from both public and private sectors. It has been highlighted that the NST (Nanoscience and Technology) education will be the most significant problem in terms of meeting the needs of qualified labor force (Roca, 2003). Owing to being a interdisciplinary area, the science discipline to provide nano-education, along with the curriculum levels details are the topics of discussion (Stevens et al., 2009). National Science Foundation of USA (NSF) provided support for a series of workshop for integrating the nanoscience and nanotechnology into the school curricula. Following a series of comprehensive studies, the subjects that are deemed suitable to be taught within the scope of nanoscience have emerged under the name of "big ideas" (Stevens et al., 2009). These subjects are as follows: Size and Scale, The Structure of Matter, Forces and Interactions, Quantum effects, Size-dependent properties, Self-Assembly, Tools and Instrumentation, Models and Simulations, Science, Technology and Society.

The motivation of this study can be described as the inadequacy of nano-education studies in our country, along with the instructors feeling incompetent due to not being familiar with this specific area. Accordingly, the objective of this research constitute a structure under the light of the international literature oriented at the manner and the concepts to be used within the content of nano-education in learning environments. What is also aimed is to synthesize the conceptual contents that will guide the nano-instructors by means of examining the international literature. What makes this study important is the popularity of nano-technology, along with its interdisciplinary nature - in other words being a field of Science, Technology, Engineering and Mathematics Education (STEM). The main problem in our study is as follows: What are the subjects/concepts that the instructors can use for nanotechnology and nanoscience teaching, and in what way can they manage to do so? The sub-questions, on the other hand, are as follows:

- What are the most useed subjects/concepts in nano-education according to the international literature?

- How is nanoteachingnology teaching done according to the international literature?

In this study, the researches carried out on nanotechnology education in the journals reviewed within the international index are examined, while also carrying out a thematic analysis on the activities implemented within the content of nanotechnology education. Thematic content analysis can be described as the interpretation of stuides on a specific subject under certain drafts within a critical approach. The subject is analyzed holistically and deeply. One of the benefits of thematic content analysis is the ensuring of synthesizing and sampling of common and similar aspects of a specific subject within the literature under a qualitative manner (Çalık \& Sözbilir, 2014).

As oriented at the examination process, the following key words were searched on the indices of Web of Science, ERIC, EBSCOhost, Education Full Text: nanotechnology, nanotechnology at schools, nanotechnology activities, nanotechnology education, etc. The articles published after 2010 have been included within the scope of the research. Owing to the fact that nanotechnology is a brand new field of study, along with the objective to identify the current status of the same in the up-to-date educational studies, this time period has been deemed to be suitable for the purposes of the study. While analyzing the data, the coding process has been carried out considering the activities implemented for the lessons, the type of learning approach used, along with the subjects/concepts on which the nanotechnology activities are projected to be carried out. Then the results have been synthesized under a holistic manner.

Following the examination carried out oriented at the manner how the nano-education is provided under the light of international literature, it can be seen that the main subjects, which were brought in by Stevens et al. (2009) under the name of "big-ideas", are endeavoured to be taught to the students. It can be seen that there are six themes standing out within the examined 
studies, which are size/scale, size-dependent properties, instrumentation used in nanotechnology, applications in nanotechnology, nano-materials, benefits and risks of nanotechnology. In order to ensure that the students comprehend the subject "nanometer", the following activities have been carried out: multimedia images under the concept of "Size and Scale"; effectiveness of objects in terms of finding their places within the nanoscale; cutting a piece of paper until reducing it to the nano-size. Oriented at describing the behavioral change of matters on nano-size, it can be seen that the activities of surface area/volume calculations, along with the tests on monolithic sizes of matters, reaction activities of the same size in smaller pieces. The imaging and characterization instrumentation has been introduced to the students, which were used in the nanotechnology studies within the content of teaching procedures. In this context, the students were taken to the nano-research centers, thus introduced with such instrumentation by the experts. Moreover, the related principles have been described through AFM and STM modelling activities, which are the two of nano-scopic tools. For the students to comprehend the underlying scientific infrastructure in the scope of creating nano-technological products, the nano-structures in the nature have been shown to them. Displaying the hydrophobic surface of the lotus plant through the activities, the nano-products and applications produced through the imitation of this structure have been integrated into the teaching studies. With the use of similar activities, the students have also been introduced with self-cleaning nano-products, LEDs, ferrofluids and nano-materials. The final session of the activities within the nano-education studies subjected to examination has ben conferred to be reserved for the discussion of benefits \& risks of nanotechnology, along with designing a nano-product, in general.

On of the challenges in integrating nanoscience and nanotechnology into education is the selection of subjects that are suitable for the levels of students. An interdisciplinary approach is deemed required in this matter (Jones et al., 2013). The most suitable level for teaching nanotechnology is conferred to be "high-school" (Chen 2012). It has been detected in the examined researches that the majority of the activities are oriented at the high school levels. It can also be seen that there are various studies carried out on the education of undergraduate students and teachers. Today, nanoscience and nanotechnology has become a fast-growing science discipline. In order to have knowledge on the nano-products we use and educate science people to be integrated into the competition of nanotechnology, it is deemed as a must to ensure the proliferation of nano-education. Owing to this need, students on various levels of education need to be introduced with basic concepts related to nanotechnology. The teachers should be subjected to nanoscience and nanotechnology education through such inservice training activities as summer camps. It is also deemed as a pertinent step to include the basic terms and concepts of nanotechnology in the science and mathematics departments of the faculties of educational sciences, providing teacher training at the level of bachelor degree. Not only could the contentrelated nanotechnology subjects be integrated into the teaching of physics, chemistry, biology and mathematics, it can also be taught through a single course such as "Science and Technology". Experiences gained through such activities will ensure the teaching of nanoscience and nanotechnology to be more effective (Furlan, 2009). For this reason, teaching of nanoscience and nanotechnology should be carried out under an applied manner through the utilization of certain activities, thus ensuring the permanent learning accordingly. 